\title{
Nuclear Quadrupole Coupling in the Rotational Spectrum of Thionyl Chloride
}

\author{
Ilona Merke and Helmut Dreizler \\ Abteilung Chemische Physik im Institut für Physikalische Chemie der Universität Kiel \\ Z. Naturforsch. 47a, 1150-1152 (1992); received September 12, 1992 \\ We report on the analysis of the chlorine quadrupole hyperfine structure of thionyl chloride, \\ $\mathrm{SO}^{35} \mathrm{Cl}^{37} \mathrm{Cl}$, observed with a molecular beam microwave Fourier transform spectrometer.
}

\section{Introduction}

Thionyl chloride, $\mathrm{SOCl}_{2}$, was the object of several investigations concerning its rotational spectrum. The rotational spectrum of the main isotopomer, $\mathrm{SO}^{35} \mathrm{Cl}_{2}$, was assigned by Burie et al. [1] and Journel et al. $[2,3]$ yielding rotational and centrifugal distortion constants. Later Dubrulle et al. [4, 5] studied the $\mathrm{SO}^{35} \mathrm{Cl}^{37} \mathrm{Cl}$ isotopomer. The ${ }^{35} \mathrm{Cl}$ quadrupole coupling constants of $\mathrm{SO}^{35} \mathrm{Cl}_{2}$ were determined by Wegner et al. [6] and confirmed by Suzuki et al. [7]. In [7] the authors also determined a $r_{0}$-structure under some assumptions and calculated the principal moments of the ${ }^{35} \mathrm{Cl}$ quadrupole coupling tensor from geometrical considerations. The $\mathrm{SO}^{37} \mathrm{Cl}_{2}$ isotopomer was assigned by Mata [8] who also improved the molecular structure.

The aim of our investigation was the precise determination of the quadrupole coupling constants of $\mathrm{SO}^{35} \mathrm{Cl}^{37} \mathrm{Cl}$ and a comparison with the coupling constants of $\mathrm{SCl}_{2}$ [9] and $\mathrm{SO}_{2} \mathrm{Cl}_{2}[10,11]$ also determined by microwave Fourier transform (MWFT) spectroscopy [12].

\section{Experimental}

We first attempted to measure the spectra with our waveguide MWFT spectrometers [13-16], but we could not get stable measuring conditions, as presumably the substance reacted with the metal surfaces of the waveguides. Many lines of $\mathrm{SO}_{2}$ were observed and overlayed the spectrum of $\mathrm{SOCl}_{2}$. Therefore we

Reprint requests to Prof. Dr. H. Dreizler, Abteilung Chemische Physik, Institut für Physikalische Chemie, Universität Kiel, Olshausenstr. 40, 2300 Kiel 1.

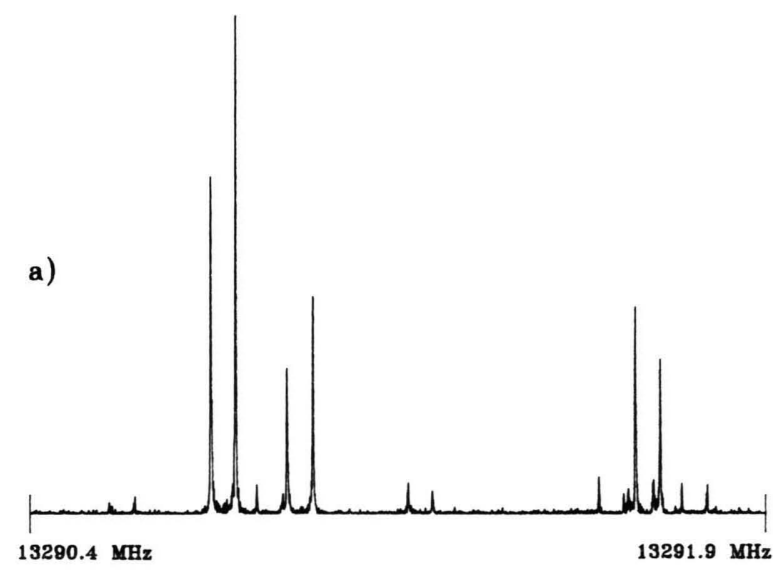

b)

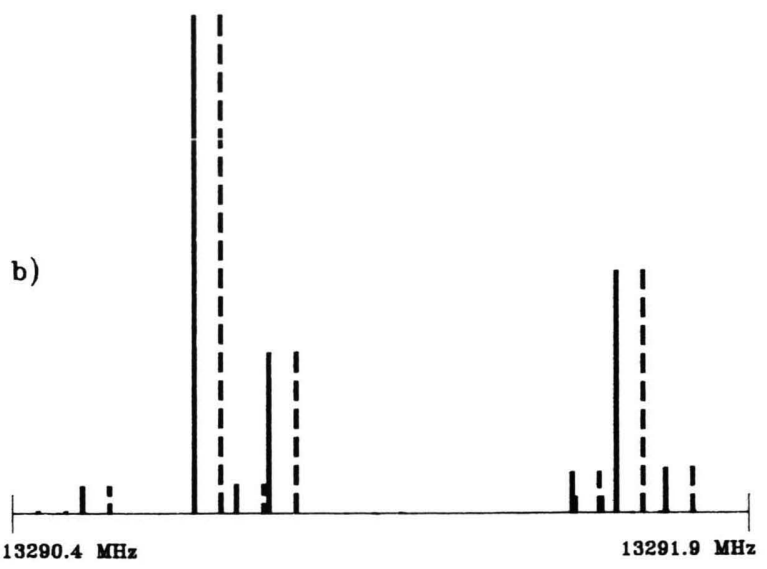

Fig. 1. A section of $1.5 \mathrm{MHz}$ out of the rotational spectrum of $\mathrm{SO}^{35} \mathrm{Cl}^{37} \mathrm{Cl}$ showing the transition $J_{K_{a} K_{c}}=2_{11}-1_{10}$. a) Polarization frequency $13291.3 \mathrm{MHz}$, backing pressure $1 \cdot 10^{6} \mathrm{~Pa}$ (760 Torr), sample interval $100 \mathrm{~ns}, 2000$ averaging cycles, 8192 data points supplemented by 24578 zeros prior Fourier transition. b) Spectrum calculated with the data of Table 2. Solid and broken lines refer to lower and higher component of the Doppler doublet.

0932-0784 / $92 / 1100-1150 \$ 01.30 / 0$. - Please order a reprint rather than making your own copy. 
Table 1. Rotational transitions of $\left[{ }^{35} \mathrm{Cl},{ }^{37} \mathrm{Cl}\right]$-thionyl chloride in the vibrational ground state. $v$ : measured frequency [MHz], $\delta_{\mathrm{hfs}}$ : observed-minus-calculated frequency of the hyperfine component $[\mathrm{kHz}], v_{0}$ : hypothetical center frequency [MHz].

\begin{tabular}{|c|c|c|c|c|c|c|c|c|c|c|c|c|c|}
\hline $\begin{array}{c}J^{\prime} K_{a}^{\prime} K_{c}^{\prime}-J K_{a} K_{c} \\
v_{0}\end{array}$ & $I^{\prime}$ & $F^{\prime}$ & $I$ & $F$ & $v$ & $\delta_{\mathrm{hfs}}$ & $\begin{array}{c}J^{\prime} K_{a}^{\prime} K_{c}^{\prime}-J K_{a} K_{c} \\
v_{0}\end{array}$ & $I^{\prime}$ & $F^{\prime}$ & $I$ & $F$ & $v$ & $\delta_{\mathrm{hfs}}$ \\
\hline 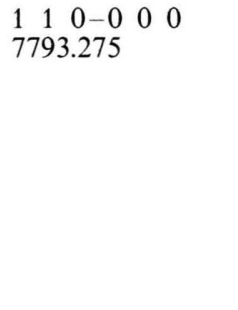 & $\begin{array}{l}1 \\
2 \\
3 \\
1 \\
2 \\
2 \\
3 \\
1 \\
0 \\
3\end{array}$ & $\begin{array}{l}0 \\
1 \\
3 \\
2 \\
3 \\
2 \\
4 \\
1 \\
1 \\
2\end{array}$ & $\begin{array}{l}1 \\
0 \\
3 \\
1 \\
2 \\
2 \\
3 \\
1 \\
2 \\
3\end{array}$ & $\begin{array}{l}1 \\
0 \\
3 \\
1 \\
2 \\
2 \\
3 \\
1 \\
2 \\
3\end{array}$ & $\begin{array}{l}7802.399 \\
7800.549 \\
7800.181 \\
7797.212 \\
7793.248 \\
7793.211 \\
7791.027 \\
7788.850 \\
7785.996 \\
7784.950\end{array}$ & $\begin{array}{r}-0.7 \\
18.2 \\
2.5 \\
-1.2 \\
-10.1 \\
-24.9 \\
26.2 \\
-1.3 \\
12.7 \\
-2.4\end{array}$ & $\begin{array}{lllll}3 & 1 & 2-2 & 0 & 2 \\
19 & 257.798\end{array}$ & $\begin{array}{l}1 \\
2 \\
3 \\
1 \\
2 \\
2 \\
3 \\
1 \\
1 \\
0\end{array}$ & $\begin{array}{l}3 \\
3 \\
2 \\
4 \\
5 \\
4 \\
3 \\
2 \\
4 \\
3\end{array}$ & $\begin{array}{l}2 \\
2 \\
3 \\
2 \\
2 \\
2 \\
3 \\
3 \\
1 \\
2\end{array}$ & $\begin{array}{l}3 \\
3 \\
2 \\
3 \\
4 \\
3 \\
2 \\
2 \\
3 \\
3\end{array}$ & $\begin{array}{ll}19 & 259.548 \\
19 & 259.204 \\
19 & 258.875 \\
19 & 258.123 \\
19 & 257.897 \\
19 & 257.677 \\
19 & 257.057 \\
19 & 256.678 \\
19 & 256.356 \\
19 & 256.212\end{array}$ & $\begin{array}{r}9.3 \\
6.6 \\
-3.9 \\
-16.7 \\
2.3 \\
-8.5 \\
-0.4 \\
1.7 \\
-3.2 \\
-4.0\end{array}$ \\
\hline $\begin{array}{lllll}2 & 1 & 1-1 & 0 & 1 \\
13 & 291.150\end{array}$ & $\begin{array}{l}3 \\
3 \\
2 \\
1 \\
3 \\
2 \\
2 \\
3\end{array}$ & $\begin{array}{l}4 \\
3 \\
4 \\
3 \\
2 \\
3 \\
2 \\
2 \\
4\end{array}$ & $\begin{array}{l}3 \\
3 \\
3 \\
1 \\
1 \\
1 \\
2 \\
2\end{array}$ & $\begin{array}{l}3 \\
3 \\
3 \\
2 \\
2 \\
2 \\
2 \\
3\end{array}$ & $\begin{array}{ll}13 & 298.335 \\
13 & 297.841 \\
13 & 297.464 \\
13 & 295.285 \\
13 & 294.847 \\
13 & 294.584 \\
13 & 291.758 \\
13 & 291.663\end{array}$ & $\begin{array}{r}-3.1 \\
-7.3 \\
-4.7 \\
17.1 \\
20.1 \\
10.3 \\
21.7 \\
-7.0\end{array}$ & & $\begin{array}{l}2 \\
3 \\
3 \\
1 \\
2 \\
3 \\
2 \\
3\end{array}$ & $\begin{array}{l}4 \\
6 \\
5 \\
3 \\
3 \\
1 \\
2 \\
2\end{array}$ & $\begin{array}{l}1 \\
3 \\
3 \\
2 \\
1 \\
3 \\
1 \\
3\end{array}$ & $\begin{array}{l}3 \\
5 \\
5 \\
2 \\
2 \\
1 \\
2 \\
1\end{array}$ & 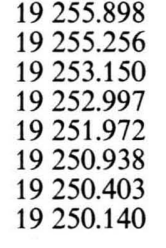 & $\begin{array}{r}-7.0 \\
16.0 \\
15.5 \\
0.8 \\
22.0 \\
-7.0 \\
-12.6 \\
-22.5\end{array}$ \\
\hline & $\begin{array}{l}1 \\
1 \\
2 \\
2 \\
2 \\
1 \\
3 \\
3 \\
0 \\
0 \\
3\end{array}$ & $\begin{array}{l}3 \\
3 \\
3 \\
3 \\
4 \\
2 \\
4 \\
5 \\
2 \\
2 \\
3\end{array}$ & $\begin{array}{l}2 \\
2 \\
2 \\
2 \\
2 \\
2 \\
2 \\
3 \\
3 \\
1 \\
0 \\
3\end{array}$ & $\begin{array}{l}3 \\
2 \\
2 \\
3 \\
3 \\
2 \\
4 \\
4 \\
1 \\
1 \\
2\end{array}$ & $\begin{array}{ll}13 & 291.649 \\
13 & 291.588 \\
13 & 290.947 \\
13 & 290.887 \\
13 & 290.793 \\
13 & 290.584 \\
13 & 289.410 \\
13 & 288.845 \\
13 & 286.746 \\
13 & 284.158 \\
13 & 283.070\end{array}$ & $\begin{array}{r}64.1 \\
-24.4 \\
28.9 \\
-3.6 \\
-7.4 \\
23.5 \\
-21.3 \\
-5.1 \\
-22.6 \\
7.9 \\
-6.9\end{array}$ & 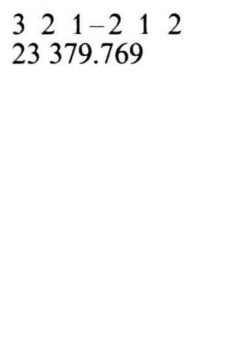 & $\begin{array}{l}3 \\
0 \\
3 \\
1 \\
2 \\
2 \\
1 \\
3 \\
2 \\
1 \\
3\end{array}$ & $\begin{array}{l}4 \\
3 \\
5 \\
2 \\
4 \\
5 \\
4 \\
6 \\
3 \\
3 \\
1\end{array}$ & $\begin{array}{l}3 \\
0 \\
3 \\
1 \\
2 \\
2 \\
1 \\
3 \\
2 \\
1 \\
3\end{array}$ & $\begin{array}{l}3 \\
2 \\
4 \\
1 \\
3 \\
4 \\
3 \\
5 \\
2 \\
2 \\
1\end{array}$ & $\begin{array}{ll}23 & 386.324 \\
23 & 385.903 \\
23 & 384.733 \\
23 & 384.520 \\
23 & 379.775 \\
23 & 379.674 \\
23 & 378.105 \\
23 & 376.522 \\
23 & 374.006 \\
23 & 372.939 \\
23 & 371.807\end{array}$ & $\begin{array}{r}20.2 \\
3.9 \\
-7.4 \\
0.9 \\
-3.5 \\
-34.5 \\
-24.4 \\
5.1 \\
4.1 \\
21.5 \\
24.0\end{array}$ \\
\hline & $\begin{array}{l}1 \\
2\end{array}$ & $\begin{array}{l}2 \\
1\end{array}$ & $\begin{array}{l}3 \\
3\end{array}$ & $\begin{array}{l}2 \\
2\end{array}$ & $\begin{array}{l}13282.427 \\
13282.385\end{array}$ & $\begin{array}{r}-2.7 \\
-18.6\end{array}$ & $\begin{array}{l}3 \begin{array}{llll}3 & 0-3 & 2 & 2 \\
13 & 686.258\end{array}\end{array}$ & $\begin{array}{l}3 \\
0\end{array}$ & $\begin{array}{l}4 \\
3\end{array}$ & $\begin{array}{l}3 \\
0\end{array}$ & $\begin{array}{l}4 \\
3\end{array}$ & $\begin{array}{l}13694.993 \\
13693.695\end{array}$ & $\begin{array}{r}-10.2 \\
-3.9\end{array}$ \\
\hline $\begin{array}{lllll}3 & 1 & 2-2 & 0 & 2 \\
19 & 257.798\end{array}$ & $\begin{array}{l}2 \\
3 \\
3 \\
0 \\
3 \\
1 \\
3 \\
3\end{array}$ & $\begin{array}{l}2 \\
3 \\
4 \\
3 \\
5 \\
2 \\
4 \\
1\end{array}$ & $\begin{array}{l}0 \\
3 \\
3 \\
0 \\
3 \\
1 \\
3 \\
3\end{array}$ & $\begin{array}{l}2 \\
3 \\
3 \\
2 \\
4 \\
1 \\
4 \\
2\end{array}$ & $\begin{array}{ll}19 & 264.316 \\
19 & 264.153 \\
19 & 263.097 \\
19 & 262.897 \\
19 & 262.073 \\
19 & 261.807 \\
19 & 261.373 \\
19 & 259.654\end{array}$ & $\begin{array}{r}-20.2 \\
-21.0 \\
8.0 \\
7.8 \\
7.4 \\
-3.1 \\
26.4 \\
-7.4\end{array}$ & & $\begin{array}{l}1 \\
3 \\
3 \\
2 \\
2 \\
1 \\
1 \\
3\end{array}$ & $\begin{array}{l}2 \\
5 \\
3 \\
4 \\
5 \\
4 \\
4 \\
2\end{array}$ & $\begin{array}{l}1 \\
3 \\
3 \\
1 \\
2 \\
2 \\
1 \\
3\end{array}$ & $\begin{array}{l}2 \\
5 \\
3 \\
4 \\
5 \\
4 \\
4 \\
1\end{array}$ & $\begin{array}{l}13691.470 \\
13691.077 \\
13689.913 \\
13686.277 \\
13686.254 \\
13685.183 \\
13685.163 \\
13681.987\end{array}$ & $\begin{array}{r}0.3 \\
0.5 \\
-13.2 \\
-2.1 \\
10.5 \\
13.1 \\
-3.9 \\
6.6\end{array}$ \\
\hline
\end{tabular}

decided to use our molecular beam (MB) MWFT spectrometer $[17,18]$.

As we did not succeed to premix the $\mathrm{SOCl}_{2}$ with argon, we soaked glass wool with the substance. It was positioned a few centimeters upstream the nozzle and exposed to a stream of argon at 1 bar. The content of the thionyl chloride argon mixture was unknown, but we estimate the concentration to be approximately $1 \%$ substance in argon. With the MB parallel to the resonator axis [18] we obtained a line width $(\mathrm{HWHH})$ of approximately $1 \mathrm{kHz}$. The line frequencies were determined as the arithmetic mean of the Doppler doublet.
The frequencies of the measured hyperfine multiplets are given in Table 1. In Fig. 1 we show the observed and calculated pattern of the $J K_{a} K_{c}=2_{11}-1_{01}$ transition.

\section{Analysis}

The quadrupole hyperfine structure (hfs) of the two coupling nuclei was analyzed with the program Q2DIAG described in [19]. The Hamiltonian matrix was set up in a coupled basis. The coupling scheme $I_{1}+I_{2}=I, I+J=F$ was used. The Hamiltonian is based on considerations in [20]. 
Table 2. Quadrupole coupling constants of $\mathrm{SO}^{35} \mathrm{Cl}^{37} \mathrm{Cl}$ in $\mathrm{MHz}$. The quadrupole coupling constants in I were determined with a fit in which the off diagonal elements were fixed at $0 \mathrm{MHz}$. In II the results of a fit are given in which one of the off diagonal elements is fitted (see text).

\begin{tabular}{lcc}
\hline & I & II \\
\hline$\chi_{a a}\left({ }^{35} \mathrm{Cl}\right)$ & $-23.008(50)$ & $-23.014(39)$ \\
$\chi_{b b}\left({ }^{35} \mathrm{Cl}\right)$ & $-2.454(99)$ & $-2.470(21)$ \\
$\chi_{c c}\left({ }^{35} \mathrm{Cl}\right)$ & $25.462(49)$ & $25.484(60)$ \\
$\left(\chi_{a c}\left({ }^{35} \mathrm{Cl}\right)\right)$ & & $(36.9(12))$ \\
$\chi_{a a}\left({ }^{37} \mathrm{Cl}\right)$ & $-21.442(57)$ & $-21.429(44)$ \\
$\chi_{b b}\left({ }^{37} \mathrm{Cl}\right)$ & $1.33(12)$ & $1.335(22)$ \\
$\chi_{c c}\left({ }^{37} \mathrm{Cl}\right)$ & $20.112(60)$ & $20.094(66)$ \\
$\left(\chi_{a c}\left({ }^{37} \mathrm{Cl}\right)\right)$ & & $(-35.0(22))$ \\
\hline
\end{tabular}

As the coupling tensors in this molecule have three off diagonal elements $\chi_{g g}, g, g^{\prime}=a, b, c, g \neq g^{\prime}$, a complex Hermitian matrix is to be diagonalized. Because of limited computer memory and time we restricted the analysis to a real Hermitian matrix and approximated the Hamiltonian first by neglection of all off diagonal elements and second by setting two of the three off diagonal elements equal to zero. By this second approximation the remaining off diagonal element is considered as an effective constant.

[1] J. Burie, J.-L. Destombes, A. Dubrulle, and G. Journel, C. R. Acad. Sci. Paris 267 B, 48 (1968).

[2] G. Journel, These Univ. Lille 1969.

[3] G. Journel, A. Dubrulle, J.-L. Destombes, and C. Maliere, C. R. Acad. Sci. Paris 271, 331 (1970).

[4] A. Dubrulle, These Science Physique, University of Lille 1972.

[5] A. Dubrulle and D. Boucher, C.R. Acad. Sci. Paris 274 B, 1426 (1972).

[6] H. K. Wenger, A. Bauder, and Hs. H. Günthard, Chem. Phys. 1, 441 (1973).

[7] S. Suzuki, M. Yamaguchi, M. Onda, T. Sakaizumi, O. Ohaski, and I. Yamaguchi, J. Mol. Struct. 73, 41 (1981).

[8] F. Mata and N. Carballo, J. Mol. Struct. 101, 233 (1983).

[9] I. Merke and H. Dreizler, Z. Naturforsch. 47 a, 1141 (1992).

[10] I. Merke and H. Dreizler, Z. Naturforsch. 47a, 1153 (1992).
The diagonal elements $\chi_{g g} g=a, b, c$ are rather insensitive to the choice of the remaining off diagonal element. Using this approximation the evaluating procedure is identical to that used for $\mathrm{SCl}_{2}[9], \mathrm{SO}_{2} \mathrm{Cl}_{2}$ [10] and $\mathrm{C}_{6} \mathrm{H}_{4} \mathrm{Cl}_{2}$ [19].

The rotational constants were fixed at the values $A=5044.34 \mathrm{MHz}, B=2748.94 \mathrm{MHz}, C=1918.70 \mathrm{MHz}$ given in [7]. The results are shown in Table 2. In column I all off diagonal elements are set to zero, in column II $\chi_{a c}\left({ }^{35} \mathrm{Cl}\right)$ and $\chi_{a c}\left({ }^{37} \mathrm{Cl}\right)$ were included in the fit. The diagonal elements are equal within the error limits.

As a determination of all off diagonal elements needs further efforts we did not determine the principal moments of the coupling tensor.

\section{Acknowledgement}

We thank the members of the Kiel group for help and discussions. Funds of the Deutsche Forschungsgemeinschaft, Fonds der Chemie, and the Land Schleswig-Holstein are gratefully acknowledged. The calculations were made at the computer center of the University of Kiel.

[11] I. Merke, Dissertation Kiel 1992.

[12] H. Dreizler, Mol. Physics 59, 1 (1986).

[13] G. Bestmann, H. Dreizler, E. Fliege, and W. Stahl, J. Mol. Struct. 97, 215 (1983).

[14] G. Bestmann and H. Dreizler, Z. Naturforsch. 37 a, 58 (1982).

[15] G. Bestmann, H. Dreizler, H. Mäder, and U. Andresen, Z. Naturforsch. 35a, 392 (1980).

[16] W. Stahl, G. Bestmann, H. Dreizler, U. Andresen, and R. Schwarz, Rev. Sci. Instrum. 56, 1759 (1985).

[17] U. Andresen, H. Dreizler, J.-U. Grabow, and W. Stahl, Rev. Sci. Instrum. 61, 3694 (1990).

[18] J.-U. Grabow and W. Stahl, Z. Naturforsch. 45a, 1043 (1990).

[19] I. Merke, Chr. Keussen, and H. Dreizler, Z. Naturforsch. 45 a, 1273 (1990).

[20] W. Gordy and R. L. Cook, Microwave Molecular Spectra, John Wiley, New York 1984, Chapter XV. 